\title{
Sarcopenia predicts adverse outcomes in an elderly population with coronary artery disease: a systematic review and meta- analysis
}

Qiqi $\mathrm{Xue}^{1+}$, Jie $\mathrm{Wu}^{1 \dagger}$, Yan $\mathrm{Ren}^{1 \dagger}$, Jiaan $\mathrm{Hu}^{1}$, Ke Yang ${ }^{2^{*}}$ and Jiumei Cao ${ }^{1 *}$

\begin{abstract}
Background: The development of sarcopenia is attributed to normal aging and factors like type 2 diabetes, obesity, inactivity, reduced testosterone levels, and malnutrition, which are factors of poor prognosis in patients with coronary artery disease (CAD). This study aimed to perform a meta-analysis to assess whether preoperative sarcopenia can be used to predict the outcomes after cardiac surgery in elderly patients with CAD.

Methods: PubMed, Embase, the Cochrane library, and Web of Science were searched for available papers published up to December 2020. The primary outcome was major adverse cardiovascular outcomes (MACE). The secondary outcomes were mortality and heart failure (HF)-related hospitalization. The random-effects model was used. Hazard ratios (HRs) with 95\% confidence intervals (95\%Cls) were estimated.

Results: Ten studies were included, with 3707 patients followed for 6 months to $4.5 \pm 2.3$ years. The sarcopenia population had a higher rate of MACE compared to the non-sarcopenia population ( $\mathrm{HR}=2.27,95 \% \mathrm{Cl}$ : 1.58-3.27, $P<0.001 ; I^{2}=60.0 \%$, $P_{\text {heterogeneity }}=0.02$ ). The association between sarcopenia and MACE was significant when using the psoas muscle area index (PMI) to define sarcopenia (HR=2.86,95\%Cl: 1.84-4.46, $P<0.001 ; I^{2}=0 \%$,

$\left.P_{\text {heterogeneity }}=0.604\right)$. Sarcopenia was not associated with higher late mortality $(H R=2.15,95 \% C l: 0.89-5.22, P=$ $0.090 ; I^{2}=91.0 \%$, $\left.P_{\text {heterogeneity }}<0.001\right)$, all-cause mortality $\left(H R=1.35,95 \% \mathrm{Cl}: 0.14-12.84, P=0.792 ; I^{2}=90.5 \%\right.$,

$\left.P_{\text {heterogeneity }}=0.001\right)$, and death, HF-related hospitalization $\left(H R=1.37,95 \% \mathrm{Cl}: 0.59-3.16, P=0.459 ; I^{2}=62.0 \%\right.$,

$P_{\text {heterogeneity }}=0.105$ ). The sensitivity analysis revealed no outlying study in the analysis of the association between sarcopenia and MACE after coronary intervention.

Conclusion: Sarcopenia is associated with poor MACE outcomes in patients with CAD. The results could help determine subpopulations of patients needing special monitoring after CAD surgery. The present study included several kinds of participants; although non-heterogeneity was found, interpretation should be cautious.
\end{abstract}

Keywords: Sarcopenia, Coronary artery disease, Outcome, Elderly, meta-analysis

\footnotetext{
* Correspondence: ykk_ykkk@126.com; cjm11261@rjh.com.cn

${ }^{\dagger}$ Qiqi Xue, Jie Wu and Yan Ren contributed equally to this work.

${ }^{2}$ Department of Vascular \& Cardiology, Ruijin Hospital, Shanghai Jiaotong

University School of Medicine, Shanghai 200025, China

'Department of Geriatrics, Ruijin Hospital, Shanghai Jiaotong University

School of Medicine, Shanghai 200025, China
}

C C The Author(s). 2021 Open Access This article is licensed under a Creative Commons Attribution 4.0 International License, which permits use, sharing, adaptation, distribution and reproduction in any medium or format, as long as you give appropriate credit to the original author(s) and the source, provide a link to the Creative Commons licence, and indicate if changes were made. The images or other third party material in this article are included in the article's Creative Commons licence, unless indicated otherwise in a credit line to the material. If material is not included in the article's Creative Commons licence and your intended use is not permitted by statutory regulation or exceeds the permitted use, you will need to obtain permission directly from the copyright holder. To view a copy of this licence, visit http://creativecommons.org/licenses/by/4.0/. The Creative Commons Public Domain Dedication waiver (http://creativecommons.org/publicdomain/zero/1.0/) applies to the data made available in this article, unless otherwise stated in a credit line to the data. 


\section{Background}

Sarcopenia is a progressive, generalized skeletal muscle disorder characterized by low muscle strength, low muscle quantity or quality, and low physical performance $[1,2]$. The prevalence of sarcopenia is estimated at $5-13 \%$ in patients of $\geq 60$ years of age and $11-50 \%$ in patients of $\geq 80$ years of age $[3,4]$. Multiple definitions and criteria of sarcopenia are available, using different cutoff points and leading to a lack of standardization and poor application of these definitions in clinical practice $[1,2]$. Still, the diagnosis of sarcopenia, using any definition of sarcopenia, is relatively straightforward since it requires the measurement of a combination of muscle mass, muscle strength, and physical performance, and since all definitions use at least two of these parameters $[1,2]$. The disease burden from sarcopenia arises from the fact that it is a relatively common condition associated with short-term and long-term adverse effects. Sarcopenia is associated with higher risks of falls and fractures [5] and is a major risk factor for loss of independence in the elderly [6]. The muscular degeneration observed in sarcopenia might ultimately impair daily life activities and adversely affect major surgery outcomes in terms of complications, morbidity, and mortality [7-12].

The development of sarcopenia is attributed to normal aging, but it has multiple aspects [13]. These aspects include type 2 diabetes, obesity, inactivity, reduced number and size of type II muscle fibers, reduced testosterone levels, malnutrition, reduced growth factor levels, and decreased muscle proteins [13-19]. In addition, any disease or condition that will decrease physical activity will contribute to sarcopenia [20-26]. Some risk factors for sarcopenia (i.e., type 2 diabetes, obesity, and inactivity) are also risk factors for coronary artery disease (CAD) [27]. Furthermore, type 2 diabetes, obesity, inactivity, reduced testosterone levels, malnutrition, and reduced growth factor levels are also factors for poor outcomes after a coronary event or after surgery [28-32]. Sarcopenia is associated with lower physical activity and respiratory muscle strength in patients with CAD [33, 34].

To date, several studies have examined sarcopenia as a prognostic factor in patients with CAD [35-37]. Still, the available studies about the impact of sarcopenia on CAD outcomes yield conflicting results [35-44], with studies suggesting a poorer prognosis of CAD in patients with sarcopenia, while other studies suggest no association or associations no longer significant after adjustment for traditional risk factors of poor prognosis. Hence, the exact contributions of sarcopenia to CADrelated health and outcomes are unknown.

We hypothesized that sarcopenia negatively affects the outcomes of elderly patients with CAD who undergo cardiac surgery. Therefore, this meta-analysis aimed to assess whether preoperative sarcopenia can be used to predict the outcomes after cardiac surgery in elderly patients with CAD. The results could help determine subpopulations of patients needing special monitoring after surgery.

\section{Methods}

Literature search

This systematic review and meta-analysis was performed according to the Preferred Reporting Items for Systematic Reviews and Meta-Analyses (PRISMA) guidelines [45]. The relevant articles were identified based on the PICO principle [46], followed by screening using the eligibility criteria. PubMed, Embase, the Cochrane library, and Web of Science were searched for available papers published up to December 2020 using the MeSH terms of 'Coronary artery disease', 'Coronary heart disease', and 'Sarcopenia', as well as relevant key words.

\section{Eligibility criteria}

The eligibility criteria were 1) population: CAD/CHD patients $\geq 65$ years of age, 2) exposure: sarcopenia, 3) non-exposure: non-sarcopenia, 4) primary outcome: major adverse cardiovascular event (MACE), 5) study type: cohort studies, and 6) language: English. Conference abstracts, editorials, comments to the editor, reviews, meta-analyses, and papers with inaccessible fulltext were excluded.

\section{Definition of MACE}

The definition of MACE could vary among studies, but MACE is generally defined as a composite endpoint including nonfatal stroke, nonfatal myocardial infarction, cardiovascular and cerebrovascular death, revascularization, and heart failure in this study $[47,48]$.

\section{Data extraction}

The data were extracted by two investigators according to a pre-specified protocol. The study characteristics (authors, year of publication, country, study design, sex, sample size, sarcopenia index, cutoff value to define sarcopenia, and follow-up duration) and outcomes (MACE, mortality, and heart failure (HF)-related hospitalization) were extracted. If a study reported hazard ratios (HRs), the adjusted HRs with 95\% confidence intervals (CIs) were extracted; otherwise, the crude HRs with 95\%CIs were obtained.

\section{Quality of the evidence}

Ten studies were included. The level of evidence of all articles was assessed independently by two authors according to the Newcastle-Ottawa Scale (NOS) criteria for quality assessment of cohort studies [49]. Discrepancies in the assessment were resolved through discussion 
until a consensus was reached. The details were summarized in Supplementary Table S1.

\section{Statistical analysis}

HRs and corresponding $95 \% \mathrm{CIs}$ were used to summarize the results. Statistical heterogeneity among studies was calculated using Cochran's Q-test and the $\mathrm{I}^{2}$ index. An $\mathrm{I}^{2}>50 \%$ and Q-test $P<0.10$ indicated high heterogeneity. The random-effects model was used to avoid possible heterogeneity among studies.
The possible publication bias was not assessed by funnel plots and Egger's test because the number of studies with MACE as the primary outcome was less than 10, in which case the funnel plots and Egger's test could yield misleading results [50,51]. A sensitivity analysis was performed by sequentially excluding each study in turn. If the $95 \% \mathrm{CI}$ of each analysis still included the HR of the initial whole analysis, the results revealed that no single study was outlying and driving the results by itself. All analyses were

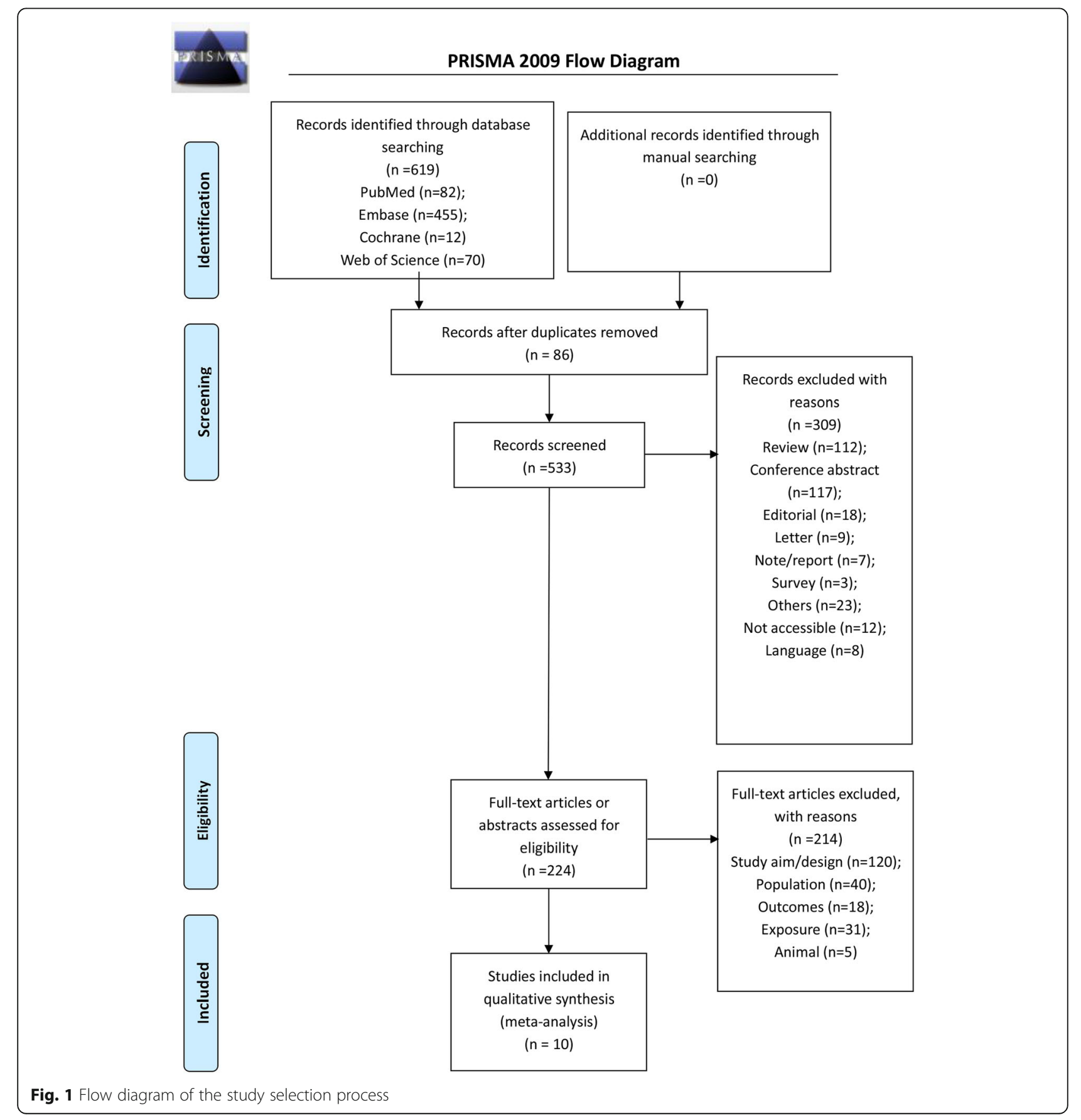


performed using STATA SE 14.0 (StataCorp, College Station, Texas, USA).

\section{Results}

\section{Selection of the studies}

Figure 1 and Supplementary Table S1 present the study selection process. The initial search yielded 483 records, and 427 records were screened after removing the duplicates. After excluding 250 records, 177 full text articles or abstracts were assessed for eligibility, and 167 were excluded (study aim/design, $n=94$; population, $n=32$; outcomes, $n=7$; exposure, $n=31$; and animal study, $n=$ $3)$.

Ten studies were included $[35,38-44,52,53]$, with a total of 3707 patients who were followed for 6 months to $4.5 \pm 2.3$ years (Supplementary Table S2). Nine studies were from Asia $[35,39-44,52,53]$ and one from the
United States of America [38]. Supplementary Table S2 shows that the definition of sarcopenia varied among the studies.

Supplementary Table S3 shows that four studies [38$40,42]$ scored 8 points on the NOS, and six studies [35, 41, 43, 44, 52, 53] scored 9 points.

\section{Sarcopenia and MACE after coronary intervention}

Seven studies [39-44, 52] analyzed the occurrence of MACE after coronary intervention. The sarcopenia population had a higher rate of MACE compared to the non-sarcopenia population $(\mathrm{HR}=2.27,95 \% \mathrm{CI}$ : $1.58-3.27, \quad P<0.001 ; \quad I^{2}=60.0 \%, \quad P_{\text {heterogeneity }}=0.02$ ) (Fig. $2 \mathrm{~A}$ and Table 1). Figure $2 \mathrm{~B}$ and Table 1 show that this association was observed in prospective cohort studies [41, 43, 44, 52] $(\mathrm{HR}=2.23,95 \% \mathrm{CI}: 1.28$ $\left.3.90, P=0.005 ; \mathrm{I}^{2}=78.8 \%, \mathrm{P}_{\text {heterogeneity }}=0.003\right)$ and

\section{A}

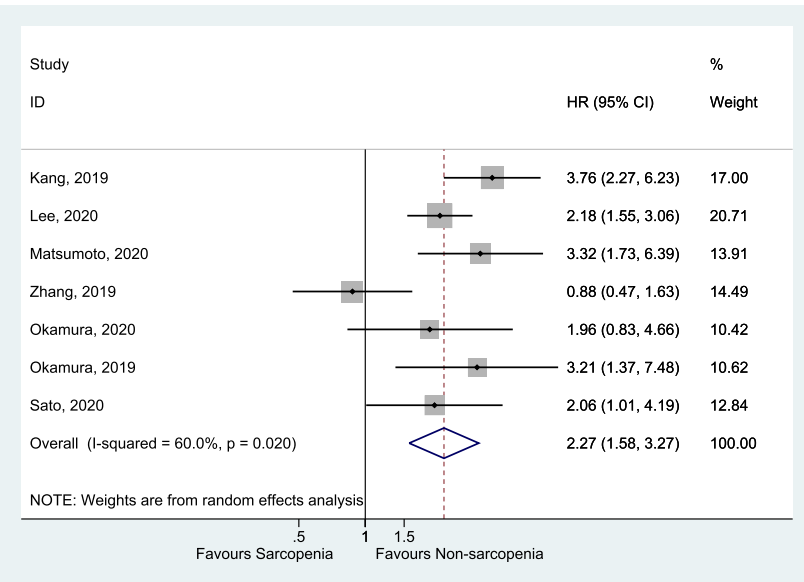

C

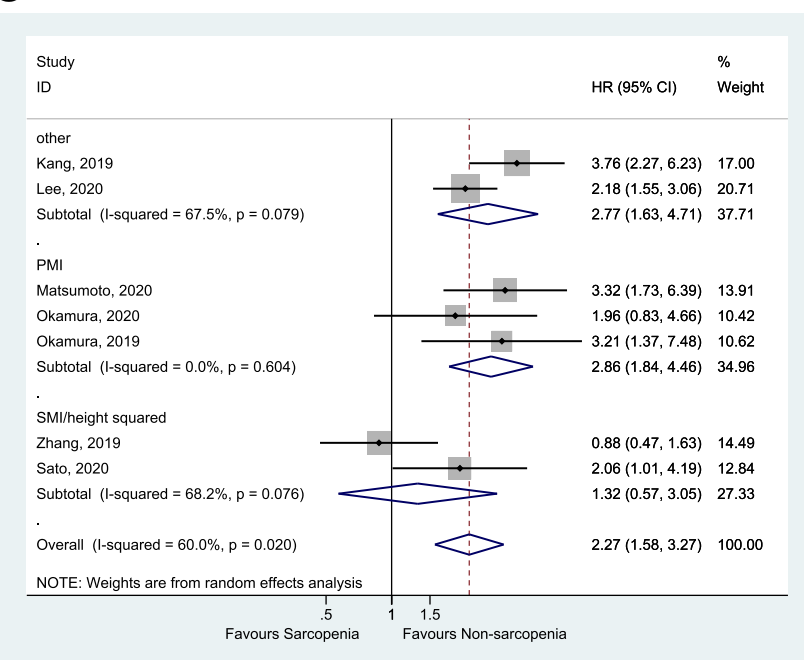

B

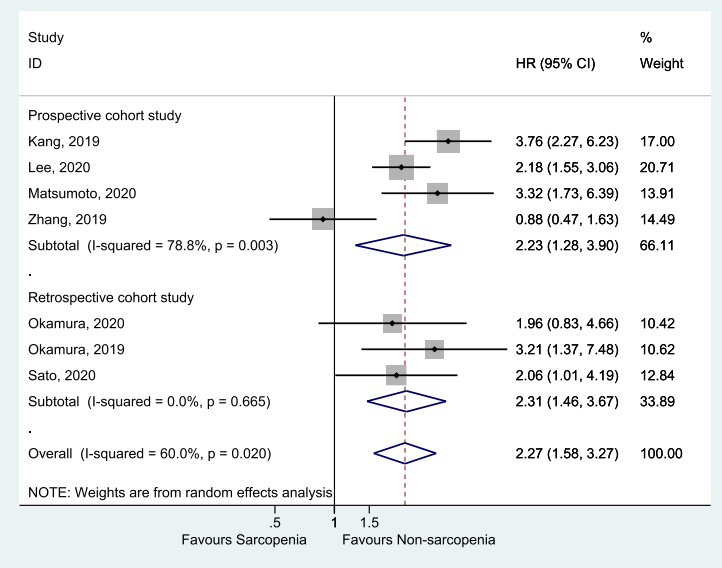

D

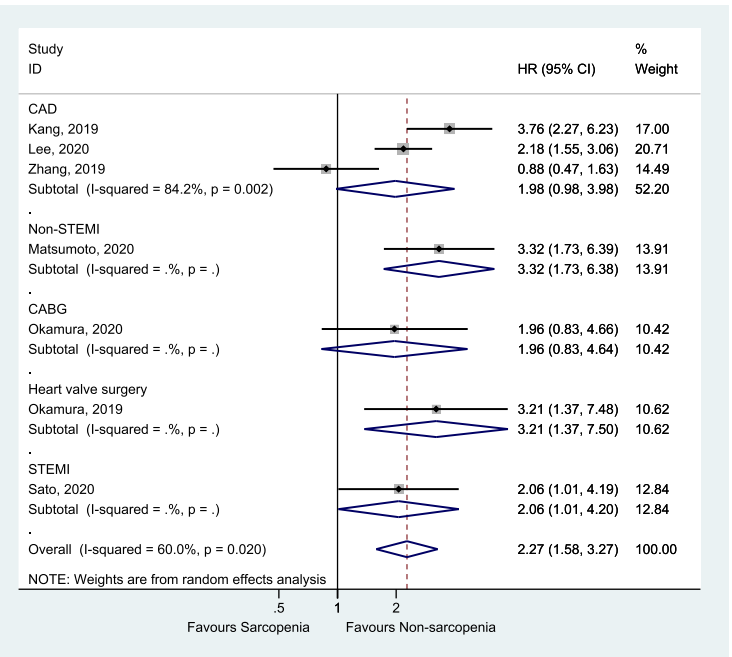

Fig. 2 A. Forest plot of MACE. B. Forest plot of Subgroup analysis of MACE by study type. C. Forest plot of subgroup analysis of MACE by sarcopenia index $\mathbf{D}$. Forest plot of subgroup analysis of MACE by diagnosis 
retrospective cohort studies [39, 40, 42] $(\mathrm{HR}=2.32$, 95\%CI: $1.46-3.67, \quad P<0.001 ; \quad \mathrm{I}^{2}=0 \%, \mathrm{P}_{\text {heterogeneity }}=$ 0.665). When considering the definitions of sarcopenia, the results showed that the association between sarcopenia and MACE was significant when using the psoas muscle area index (PMI) to define sarcopenia $[39,40,52] \quad(\mathrm{HR}=2.86,95 \% \mathrm{CI}: 1.84-4.46, P<0.001$; $\left.\mathrm{I}^{2}=0 \%, \mathrm{P}_{\text {heterogeneity }}=0.604\right)$ (Fig. $2 \mathrm{C}$ and Table 1 ), but not when using the skeletal muscle area index (SMI)/height squared $[41,42] \quad(\mathrm{HR}=1.32,95 \% \mathrm{CI}$ : $0.57-3.05, \quad P=0.518 ; \quad I^{2}=68.2 \%, \quad P_{\text {heterogeneity }}=0.076$ ) (Fig. 2C and Table 1); the association was also observed when using definitions other than the PMI or SMI/height squared [43, 44] $(\mathrm{HR}=2.77,95 \% \mathrm{CI}: 1.63-$ 4.71, $P<0.001 ; \mathrm{I}^{2}=67.5 \%, \mathrm{P}_{\text {heterogeneity }}=0.079$ ) (Fig. $2 \mathrm{C}$ and Table 1$)$.

\section{Sarcopenia, mortality, and HF-related hospitalization after coronary intervention}

Sarcopenia was not associated with higher late mortality [38-40] $\left(\mathrm{HR}=2.15,95 \% \mathrm{CI}: 0.89-5.22, P=0.090 ; \mathrm{I}^{2}=\right.$ 91.0\%, $\mathrm{P}_{\text {heterogeneity }}<0.001$ ) (Fig. 3 and Table 1), all-cause mortality $[41,43](\mathrm{HR}=1.35,95 \% \mathrm{CI}: 0.14-12.84, P=$ $0.792 ; \mathrm{I}^{2}=90.5 \%$, Pheterogeneity $\left.=0.001\right)$ (Fig. 4 and Table $1)$, and death, HF-related hospitalization $[35,53](\mathrm{HR}=$ 1.37, 95\%CI: $0.59-3.16, P=0.459 ; \mathrm{I}^{2}=62.0 \%$, $\mathrm{P}_{\text {heterogene- }}$ ity $=0.105)($ Fig. 5 and Table 1).

\section{Sensitivity analysis}

The sensitivity analysis suggested that there was no outlying study in the analysis of the association between sarcopenia and MACE after coronary intervention (Fig. 6).

\section{Discussion}

The available studies about the impact of sarcopenia on the outcomes of CAD yield conflicting results. Hence, this meta-analysis aimed to assess whether preoperative sarcopenia can be used to predict the outcomes after cardiac surgery in elderly patients with CAD. The results showed that sarcopenia is associated with poor MACE outcomes in patients with CAD.

These findings highlight the importance of performing a routine physical assessment for risk stratification and sarcopenia in CAD patients. In this context, sarcopenia is a functional status to be detected early in clinical practice, and the importance of PMI is indispensable for identifying simple methods. This is important since a recent meta-analysis showed that sarcopenia could be observed in $31.4 \%$ of patients with CAD [54]. Sarcopenia has also been associated with hypertension in older adults [55], with type 2 diabetes [26, 56, 57], and obesity $[58,59]$. Hypertension, diabetes, and obesity are also risk factors for the occurrence of CAD [27, 60-62] but are also well-known factors for adverse outcomes in patients with CAD [62-65]. In addition, other factors associated with the development of sarcopenia are also risk factors for poor outcomes after surgery. Indeed, low testosterone levels are associated with increased mortality after CAD and after surgery for CAD [66, 67]. Malnutrition is a factor of poor prognosis in hospitalized patients [68, 69]. Low levels of growth factors are also related to poor outcomes after CAD and surgery [70, 71].

Table 1 Adverse outcomes for sarcopenia versus non-sarcopenia

\begin{tabular}{|c|c|c|c|c|c|}
\hline & $\mathrm{N}$ & HR $(95 \% \mathrm{Cl})$ & $\mathbf{P}$ & $\mathrm{I}^{2}, \%$ & $P_{(\text {Heterogeneity) }}$ \\
\hline MACE overall & 7 & $2.273(1.581-3.268)$ & $<0.001$ & 60 & 0.02 \\
\hline Other & 2 & $2.769(1.630-4.706)$ & $<0.001$ & 67.5 & 0.079 \\
\hline PMl & 3 & $2.861(1.835-4.460)$ & $<0.001$ & 0 & 0.604 \\
\hline SMI/height squared & 2 & $1.319(0.570-3.050)$ & 0.518 & 68.2 & 0.076 \\
\hline Prospective cohort & 4 & $2.232(1.278-3.898)$ & 0.005 & 78.8 & 0.003 \\
\hline Retrospective cohort & 3 & $2.315(1.460-3.670)$ & $<0.001$ & 0 & 0.665 \\
\hline CAD & 3 & $1.979(0.984-3.983)$ & 0.056 & 84.2 & 0.002 \\
\hline Non-STEMI & 1 & $3.320(1.727-6.381)$ & $<0.001$ & & \\
\hline CABG & 1 & $1.960(0.827-4.644)$ & 0.126 & & \\
\hline Heart valve surgery & 1 & $3.210(1.374-7.501)$ & 0.007 & & \\
\hline STEMI & 1 & $2.060(1.011-4.196)$ & 0.046 & & \\
\hline Late mortality & 3 & $2.152(0.887-5.223)$ & 0.09 & 91 & $<0.001$ \\
\hline Heart valve surgery & 2 & $1.548(0.7-3.422)$ & 0.281 & 85.2 & 0.009 \\
\hline CABG & 1 & $4.250(2.181-8.283)$ & $<0.001$ & & \\
\hline Death, HF-related hospitalization & 2 & $1.370(0.594-3.164)$ & 0.459 & 62 & 0.105 \\
\hline All-cause mortality & 2 & $1.354(0.143-12.842)$ & 0.792 & 90.5 & 0.001 \\
\hline
\end{tabular}

$H R$ hazard ratio, $C I$ confidence interval, $M A C E$ major adverse cardiovascular event, $P M I$ psoas muscle area index, $S M I$ skeletal muscle area index, $C A D$ coronary artery disease, STEMI ST-elevated myocardial infarction, CABG coronary artery bypass graft, $H F$ heart failure 


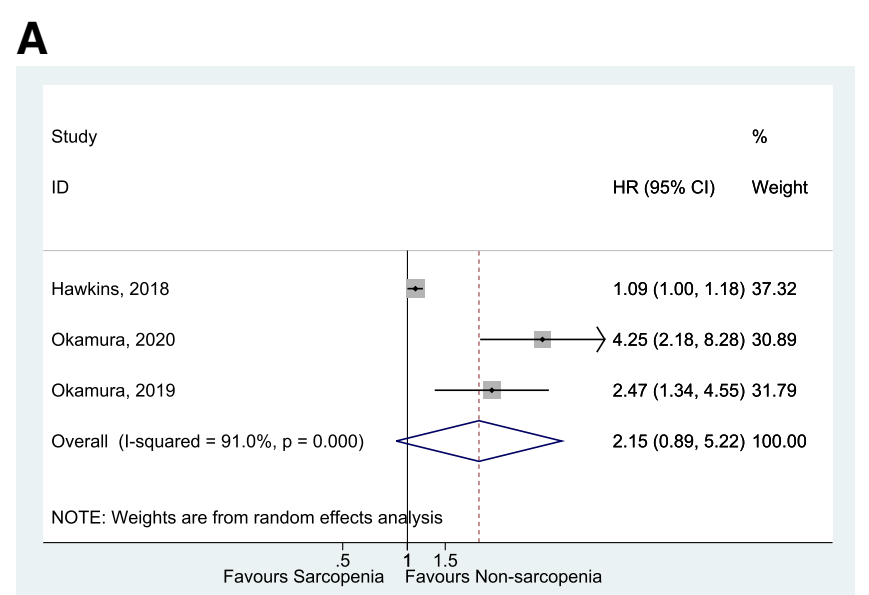

B

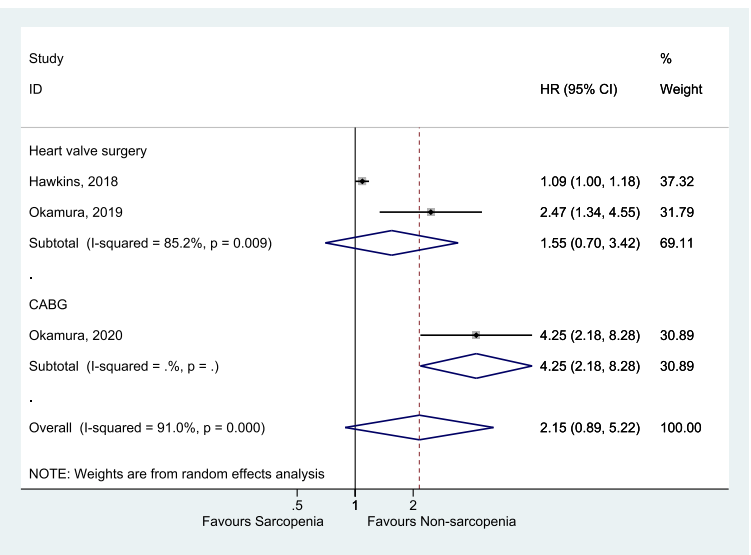

Fig. 3 A. Forest plot of late mortality. B. Forest plot of subgroup analysis of late mortality by diagnosis

Still, this study showed that only the MACEs after coronary intervention for CAD were affected by sarcopenia, while mortality was not associated. Previous metaanalyses showed that sarcopenia is a risk factor for mortality in the general elderly population [72-74] and a factor of poor prognosis in cancer patients $[75,76]$. No previous meta-analysis examined specifically the impact of sarcopenia on MACEs and mortality after coronary intervention. Still, a previous meta-analysis showed that handgrip strength was associated with CAD in the community [77], but a prospective study showed no such association [78]. Still, an association with an increased risk of MACE, even in the absence of increased mortality, signifies a higher disease burden and lower quality of life for the patients $[79,80]$ and higher healthcare costs for the patients, their family, and society [81].

This meta-analysis revealed wide differences among studies (and even within a single country) regarding the definition of sarcopenia, and these definitions affected the association of sarcopenia with the primary outcome (MACEs). Liu et al. [72] also showed that the method for determining sarcopenia, dual X-ray absorptiometry vs. bioelectrical impedance analysis in their case, affected their results of the association between sarcopenia and all-cause mortality. A recent meta-analysis highlighted the need for the proper diagnosis of sarcopenia and that properly diagnosed sarcopenia was associated with the outcomes after major gastrointestinal surgery [82].

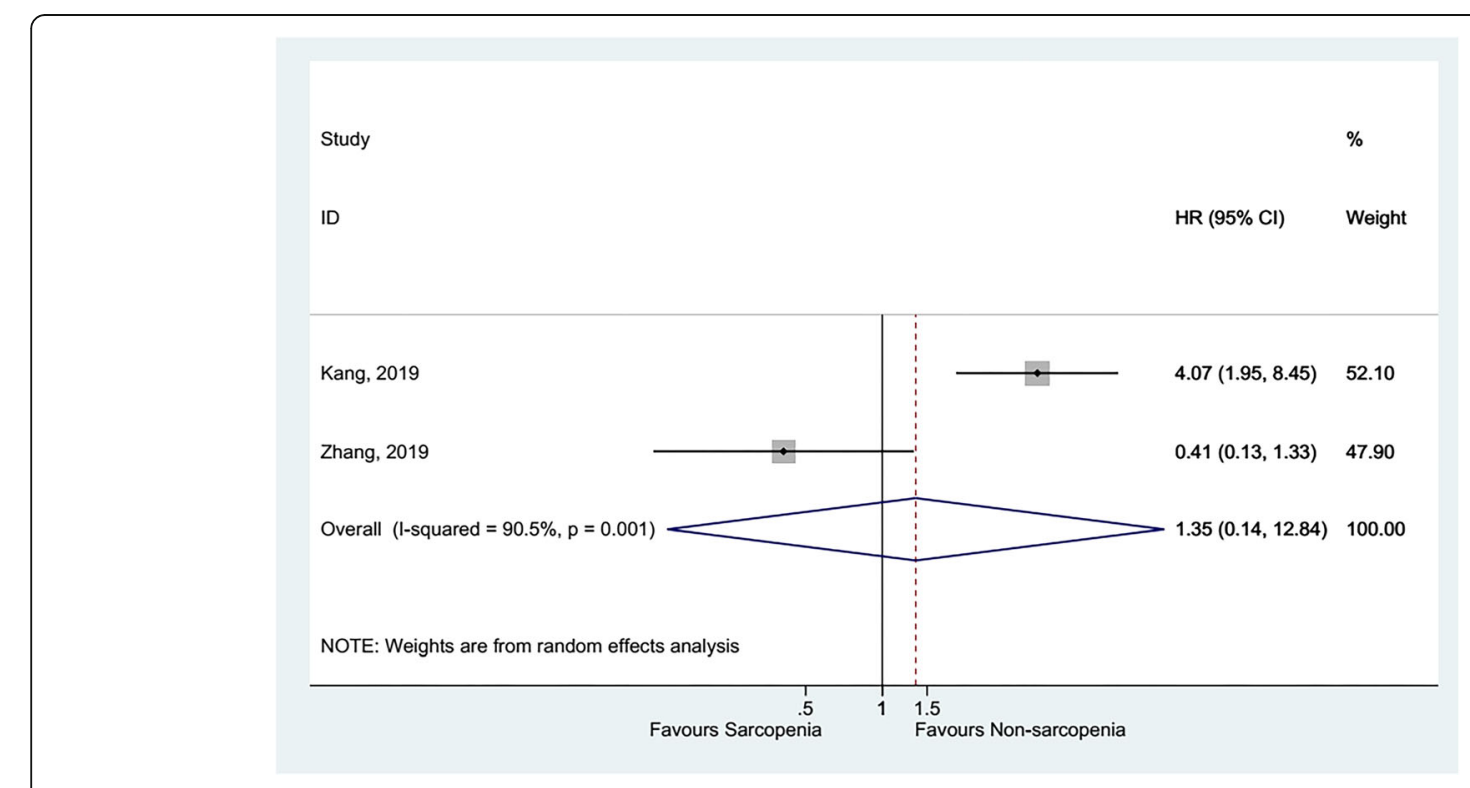

Fig. 4 Forest plot of All-cause mortality 
Study

ID
$\%$

$\mathrm{HR}(95 \% \mathrm{Cl}) \quad$ Weight

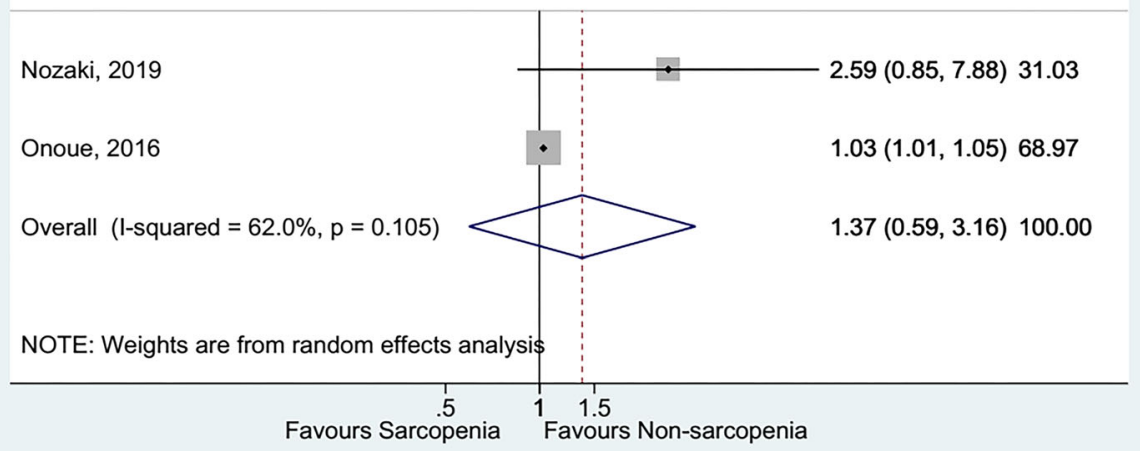

Fig. 5 Forest plot of Death, HF-related hospitalization

The conclusions of this meta-analysis must be considered along with its limitations. Indeed, metaanalyses inherit all the included studies' limitations, and some caveats should be considered while interpreting the findings. Because of non-randomized registry data's intrinsic limitations, the differences in baseline characteristics between groups can affect the outcome. To minimize such biases, two studies [40, 43] performed propensity score-matched analyses, and others used a multivariable logistic regression model. Second, the included sample of 3707 patients was relatively large. Finally, studies that used other and PMI to define sarcopenia demonstrated that the sarcopenia population has a higher MACE rate compared with the non-sarcopenia population. Still, studies performed using SMI/height squared index did not observe the statistical difference between the two groups. Nevertheless, the sensitivity analysis

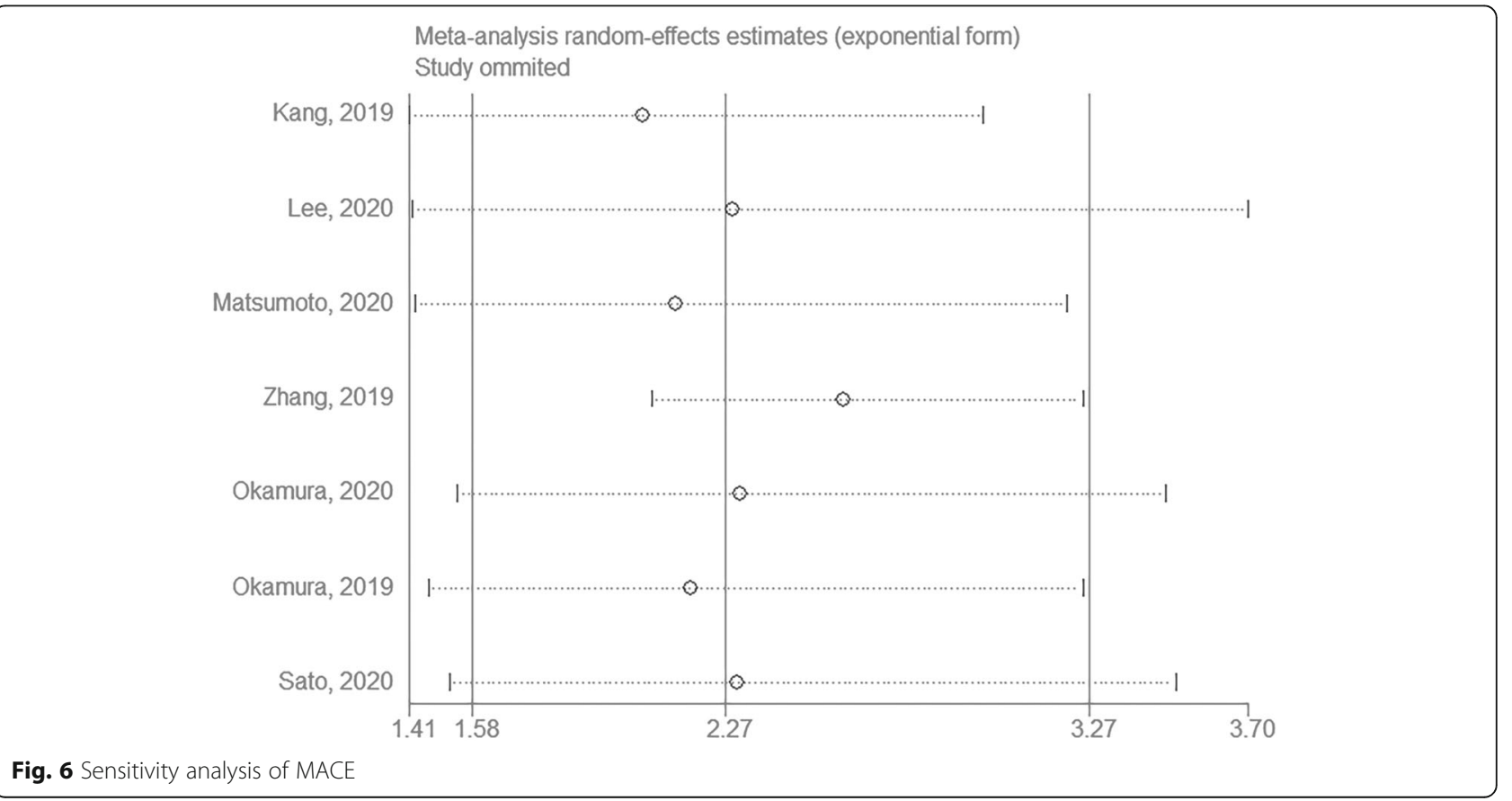


demonstrated no outlying study. Future studies should look to reconcile these definitions of sarcopenia.

A major limitation is that suitable cutoff values for sarcopenia potentially differ among races, sexes, and age groups. In addition, there are many different cutoff values used for the definition of sarcopenia in the literature. Thus, it is difficult to obtain a universal definition of sarcopenia. The cutoff value for sarcopenia was defined as the lowest quartile in most studies [38, 40, 42, 44]. In contrast, some of the other studies performed a receiver operating characteristic (ROC) curve analysis to obtain the optimal cutoff value to define sarcopenia [43, 52]. Because of heterogeneity, a sensitivity analysis was performed and demonstrated no outlying study. In addition, the present study included several kinds of participants such as CAD, NSTEMI/STMI, HF, off-pump CABG, and heart valve surgery. Although non-heterogeneity was found, interpretation should be cautious.

\section{Conclusion}

In conclusion, sarcopenia is associated with poor MACE outcomes in patients with CAD. Still, the definitions of sarcopenia were different among the included studies. Future studies should look to standardize the definition of sarcopenia to achieve better estimations of the associations of sarcopenia with adverse outcomes. Although non-heterogeneity was found, interpretation should be cautious because various types of patients were included.

\section{Abbreviations \\ CAD: Coronary artery disease; Cls: Confidence intervals; HF: Heart failure; HRs: Hazard ratios; MACE: Major adverse cardiovascular event; NOS: Newcastle-Ottawa Scale; PRISMA: Preferred Reporting Items for Systematic Reviews and Meta-Analyses; ROC: Receiver operating characteristic; SMI: Skeletal muscle area index}

\section{Supplementary Information}

The online version contains supplementary material available at https://doi. org/10.1186/s12877-021-02438-w.

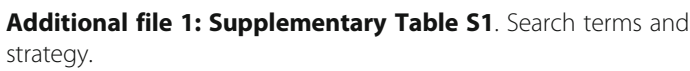

Additional file 2: Supplementary Table S2. Literature search and study characteristic.

Additional file 3: Supplementary Appendix S3. NOS criteria for quality of cohort studies.

\section{Acknowledgments}

Not applicable.

\section{Authors' contributions}

Study concept: JMC and KY. Study design: JMC, KY, and QQX. Data acquisition: QQX, JW, and YR. Quality control of data and algorithms: JMC and KY. Data analysis and interpretation: QQX, YR, and JAH. Manuscript preparation: QQX and JW. Manuscript editing: YR and JAH. Manuscript review: JMC and KY. All authors (QQX, JW, YR, JAH, KY, and JMC) have read and approved the final version of the manuscript.

\section{Funding}

Shanghai Jiaotong University School of Medicine [TM201805], The funding bodies had no role in the design of the study and collection, analysis, and interpretation of data and in writing the manuscript.

Availability of data and materials

All data generated or analyzed during this study are included in this published article and its supplementary information files.

\section{Declarations}

Ethics approval and consent to participate

Not applicable.

\section{Consent for publication}

Not applicable.

\section{Competing interests}

The authors declare that they have no conflict of interest.

Received: 26 March 2021 Accepted: 26 August 2021

Published online: 14 September 2021

\section{References}

1. Cruz-Jentoft AJ, Bahat G, Bauer J, Boirie Y, Bruyere O, Cederholm T, et al. Sarcopenia: revised European consensus on definition and diagnosis. Age Ageing. 2019;48(1):16-31. https://doi.org/10.1093/ageing/afy169.

2. Ardeljan AD, Hurezeanu R. Sarcopenia. In: StatPearls: Treasure Island (FL); 2020.

3. von Haehling S, Morley JE, Anker SD. An overview of sarcopenia: facts and numbers on prevalence and clinical impact. J Cachexia Sarcopenia Muscle 2010;1(2):129-33. https://doi.org/10.1007/s13539-010-0014-2.

4. Shafiee G, Keshtkar A, Soltani A, Ahadi Z, Larijani B, Heshmat R. Prevalence of sarcopenia in the world: a systematic review and meta- analysis of general population studies. J Diabetes Metab Disord. 2017;16(1):21. https:// doi.org/10.1186/s40200-017-0302-x.

5. Yeung SSY, Reijnierse EM, Pham VK, Trappenburg MC, Lim WK, Meskers CGM, et al. Sarcopenia and its association with falls and fractures in older adults: a systematic review and meta-analysis. J Cachexia Sarcopenia Muscle. 2019;10(3):485-500. https://doi.org/10.1002/jcsm.12411.

6. Dos Santos L, Cyrino ES, Antunes M, Santos DA, Sardinha LB. Sarcopenia and physical independence in older adults: the independent and synergic role of muscle mass and muscle function. J Cachexia Sarcopenia Muscle. 2017;8(2):245-50. https://doi.org/10.1002/jcsm.12160.

7. Santilli V, Bernetti A, Mangone M, Paoloni M. Clinical definition of sarcopenia. Clin Cases Miner Bone Metab. 2014;11(3):177-80. https://doi. org/10.11138/ccmbm/2014.11.3.177.

8. Kim EY, Lee HY, Kim KW, Lee Jl, Kim YS, Choi WJ, et al. Preoperative computed tomography-determined sarcopenia and postoperative outcome after surgery for non-small cell lung Cancer. Scand J Surg. 2018;107(3):24451. https://doi.org/10.1177/1457496917748221.

9. Rangel EL, Rios-Diaz AJ, Uyeda JW, Castillo-Angeles M, Cooper Z, Olufajo $\mathrm{OA}$, et al. Sarcopenia increases risk of long-term mortality in elderly patients undergoing emergency abdominal surgery. J Trauma Acute Care Surg. 2017;83(6):1179-86. https://doi.org/10.1097/TA.0000000000001657.

10. El Amrani M, Vermersch M, Fulbert M, Prodeau M, Lecolle K, Hebbar M, et al. Impact of sarcopenia on outcomes of patients undergoing pancreatectomy: a retrospective analysis of 107 patients. Medicine (Baltimore). 2018;97(39): e12076. https://doi.org/10.1097/MD.0000000000012076.

11. Kaido $T$, Hamaguchi $Y$, Uemoto $S$. Significance of preoperative sarcopenia to liver surgery. Hepatobiliary Surg Nutr. 2019;8(1):59-62. https://doi.org/10.21 037/hbsn.2018.11.05

12. Huang DD, Wang SL, Zhuang CL, Zheng BS, Lu JX, Chen FF, et al. Sarcopenia, as defined by low muscle mass, strength and physical performance, predicts complications after surgery for colorectal cancer. Color Dis. 2015;17(11):O256-64. https://doi.org/10.1111/codi.13067.

13. Lexell J, Henriksson-Larsen K, Winblad B, Sjostrom M. Distribution of different fiber types in human skeletal muscles: effects of aging studied in whole muscle cross sections. Muscle Nerve. 1983:6(8):588-95. https://doi. org/10.1002/mus.880060809. 
14. Visser M, Harris TB, Langlois J, Hannan MT, Roubenoff R, Felson DT, et al. Body fat and skeletal muscle mass in relation to physical disability in very old men and women of the Framingham heart study. J Gerontol A Biol Sci Med Sci. 1998;53(3):M214-21. https://doi.org/10.1093/gerona/53A.3.M214.

15. Morley JE. Hormones and the aging process. J Am Geriatr Soc. 2003;51(7 Suppl):S333-7. https://doi.org/10.1046/j.1365-2389.2003.51344.x.

16. Vermeulen A, Goemaere S, Kaufman JM. Testosterone, body composition and aging. J Endocrinol Investig. 1999;22(5 Suppl):110-6.

17. Schrager MA, Metter EJ, Simonsick E, Ble A, Bandinelli S, Lauretani F, et al. Sarcopenic obesity and inflammation in the InCHIANTI study. J Appl Physiol (1985). 2007;102(3):919-25.

18. Dickinson JM, Volpi E, Rasmussen BB. Exercise and nutrition to target protein synthesis impairments in aging skeletal muscle. Exerc Sport Sci Rev. 2013;41(4):216-23. https://doi.org/10.1097/JES.0b013e3182a4e699.

19. Granic A, Mendonca N, Sayer AA, Hill TR, Davies K, Siervo M, et al. Effects of dietary patterns and low protein intake on sarcopenia risk in the very old: the Newcastle 85+ study. Clin Nutr. 2020;39(1):166-73. https://doi.org/10.101 6/j.clnu.2019.01.009.

20. Fielding RA, Vellas B, Evans WJ, Bhasin S, Morley JE, Newman AB, et al. Sarcopenia: an undiagnosed condition in older adults. Current consensus definition: prevalence, etiology, and consequences. International working group on sarcopenia. J Am Med Dir Assoc. 2011;12(4):249-56. https://doi. org/10.1016/j.jamda.2011.01.003.

21. Kim SH, Shin MJ, Shin YB, Kim KU. Sarcopenia associated with chronic obstructive pulmonary disease. J Bone Metab. 2019;26(2):65-74. https://doi. org/10.11005/jbm.2019.26.2.65

22. Abdul Aziz SA, McStea M, Ahmad Bashah NS, Chong ML, Ponnampalavanar S, Syed Omar SF, et al. Assessment of sarcopenia in virally suppressed HIVinfected Asians receiving treatment. AIDS. 2018;32(8):1025-34. https://doi. org/10.1097/QAD.0000000000001798.

23. Curcio F, Testa G, Liguori I, Papillo M, Flocco V, Panicara V, et al. Sarcopenia and Heart Failure. Nutrients. 2020;12(1). https://doi.org/10.3390/nu12010211.

24. Souza VA, Oliveira D, Mansur HN, Fernandes NM, Bastos MG. Sarcopenia in chronic kidney disease. J Bras Nefrol. 2015;37(1):98-105. https://doi.org/10. 5935/0101-2800.20150014.

25. Dunne RF, Loh KP, Williams GR, Jatoi A, Mustian KM, Mohile SG. Cachexia and Sarcopenia in Older Adults with Cancer: A Comprehensive Review. Cancers (Basel). 2019;11(12). https://doi.org/10.3390/cancers11121861.

26. Mesinovic J, Zengin A, De Courten B, Ebeling PR, Scott D. Sarcopenia and type 2 diabetes mellitus: a bidirectional relationship. Diabetes Metab Syndr Obes. 2019;12:1057-72. https://doi.org/10.2147/DMSO.S186600.

27. Authors/Task Force M, Piepoli MF, Hoes AW, Agewall S, Albus C, Brotons C, et al. 2016 European Guidelines on cardiovascular disease prevention in clinical practice: The Sixth Joint Task Force of the European Society of Cardiology and Other Societies on Cardiovascular Disease Prevention in Clinical Practice (constituted by representatives of 10 societies and by invited experts): Developed with the special contribution of the European Association for Cardiovascular Prevention \& Rehabilitation (EACPR). Eur J Prev Cardiol. 2016;23(11):NP1-NP96.

28. Karaye KM, Sani MU. Factors associated with poor prognosis among patients admitted with heart failure in a Nigerian tertiary medical Centre: a cross-sectional study. BMC Cardiovasc Disord. 2008;8(1):16. https://doi.org/1 0.1186/1471-2261-8-16

29. Iscen S. Prognostic factors in patients with acute coronary syndrome without ST-segment elevation. Arq Bras Cardiol. 2013;101(4):373-4. https:// doi.org/10.5935/abc.20130198.

30. Wang $R$, Mei B, Liao X, Lu X, Yan L, Lin M, et al. Determination of risk factors affecting the in-hospital prognosis of patients with acute ST segment elevation myocardial infarction after percutaneous coronary intervention. BMC Cardiovasc Disord. 2017;17(1):243. https://doi.org/10.1186/s12872-0170660-9.

31. Chakravarthy M. Modifying risks to improve outcome in cardiac surgery: an anesthesiologist's perspective. Ann Card Anaesth. 2017;20(2):226-33. https:// doi.org/10.4103/aca.ACA_20_17.

32. Zeitouni M, Clare RM, Chiswell K, Abdulrahim J, Shah N, Pagidipati NP, et al. Risk factor burden and long-term prognosis of patients with premature coronary artery disease. J Am Heart Assoc. 2020;9(24):e017712. https://doi. org/10.1161/JAHA.120.017712.

33. Izawa KP, Watanabe S, Oka K, Kasahara Y, Morio Y, Hiraki K, et al. Sarcopenia and physical activity in older male cardiac patients. Int J Cardiol. 2016;222: 457-61. https://doi.org/10.1016/j.ijcard.2016.07.167.
34. Izawa KP, Watanabe S, Oka K, Kasahara Y, Morio Y, Hiraki K, et al. Respiratory muscle strength in relation to sarcopenia in elderly cardiac patients. Aging Clin Exp Res. 2016;28(6):1143-8. https://doi.org/10.1007/s40520-016-0534-5.

35. Onoue $Y$, Izumiya $Y$, Hanatani $S$, Tanaka T, Yamamura $S$, Kimura $Y$, et al. A simple sarcopenia screening test predicts future adverse events in patients with heart failure. Int J Cardiol. 2016;215:301-6. https://doi.org/10.1016/j.ijca rd.2016.04.128.

36. Narumi T, Watanabe T, Kadowaki S, Takahashi T, Yokoyama M, Kinoshita D, et al. Sarcopenia evaluated by fat-free mass index is an important prognostic factor in patients with chronic heart failure. Eur J Intern Med 2015;26(2):118-22. https://doi.org/10.1016/j.ejim.2015.01.008.

37. Anker SD, Ponikowski P, Varney S, Chua TP, Clark AL, Webb-Peploe KM, et al. Wasting as independent risk factor for mortality in chronic heart failure. Lancet. 1997;349(9058):1050-3. https://doi.org/10.1016/S0140-6736(96)0701 5-8

38. Hawkins RB, Mehaffey JH, Charles EJ, Kern JA, Lim DS, Teman NR, et al. Psoas muscle size predicts risk-adjusted outcomes after surgical aortic valve replacement. Ann Thorac Surg. 2018;106(1):39-45. https://doi.org/10.1016/j.a thoracsur.2018.02.010.

39. Okamura H, Kimura N, Mieno M, Yuri K, Yamaguchi A. Preoperative sarcopenia is associated with late mortality after off-pump coronary artery bypass grafting. Eur J Cardiothorac Surg. 2020;58(1):121-9. https://doi.org/1 0.1093/ejcts/ezz378

40. Okamura H, Kimura N, Tanno K, Mieno M, Matsumoto $H$, Yamaguchi A, et al. The impact of preoperative sarcopenia, defined based on psoas muscle area, on long-term outcomes of heart valve surgery. J Thorac Cardiovasc Surg. 2019;157(3):1071-9 e1073. https://doi.org/10.1016/j.jtcvs.2018.06.098.

41. Zhang N, Zhu WL, Liu XH, Chen W, Zhu ML, Kang L, et al. Prevalence and prognostic implications of sarcopenia in older patients with coronary heart disease. J Geriatr Cardiol. 2019;16(10):756-63. https://doi.org/10.11909/j.issn.1 671-5411.2019.10.002.

42. Sato R, Akiyama E, Konishi M, Matsuzawa Y, Suzuki H, Kawashima C, et al. Decreased appendicular skeletal muscle mass is associated with poor outcomes after ST-segment elevation myocardial infarction. J Atheroscler Thromb. 2020;27(12):1278-87. https://doi.org/10.5551/jat.52282.

43. Kang DO, Park SY, Choi BG, Na JO, Choi CU, Kim EJ, et al. Prognostic Impact of Low Skeletal Muscle Mass on Major Adverse Cardiovascular Events in Coronary Artery Disease: A Propensity Score-Matched Analysis of a Single Center All-Comer Cohort. J Clin Med. 2019;8(5). https://doi.org/10.3390/ jcm8050712.

44. Lee HS, Park KW, Kang J, Ki YJ, Chang M, Han JK, et al. Sarcopenia Index as a Predictor of Clinical Outcomes in Older Patients with Coronary Artery Disease. J Clin Med. 2020;9(10). https://doi.org/10.3390/jcm9103121.

45. Selcuk AA. A guide for systematic reviews: PRISMA. Turkish Arch Otorhinolaryngol. 2019:57(1):57-8. https://doi.org/10.5152/tao.2019.4058.

46. Aslam S, Emmanuel P. Formulating a researchable question: a critical step for facilitating good clinical research. Indian J Sexually Transmitted Dis AIDS. 2010;31(1):47-50. https://doi.org/10.4103/0253-7184.69003.

47. de Jong $M$, van der Worp HB, van der Graaf $Y$, Visseren FL, Westerink J. Pioglitazone and the secondary prevention of cardiovascular disease. A meta-analysis of randomized-controlled trials. Cardiovasc Diabetol. 2017; 16(1):134

48. Arnott C, Li Q, Kang A, Neuen BL, Bompoint S, Lam CSP, et al. Sodiumglucose cotransporter 2 inhibition for the prevention of cardiovascular events in patients with type 2 diabetes mellitus: a systematic review and Meta-analysis. J Am Heart Assoc. 2020;9(3):e014908. https://doi.org/10.1161/ JAHA.119.014908.

49. Lo CK, Mertz D, Loeb M. Newcastle-Ottawa scale: comparing reviewers' to authors' assessments. BMC Med Res Methodol. 2014;14(1):45. https://doi. org/10.1186/1471-2288-14-45.

50. Higgins JP, Altman DG, Gotzsche PC, Juni P, Moher D, Oxman AD, et al. The Cochrane Collaboration's tool for assessing risk of bias in randomised trials. Bmj. 2011;343(oct18 2):d5928. https://doi.org/10.1136/bmj.d5928.

51. Higgins JPT, Thomas J, Chandler J, Cumpston M, Li T, Page MJ, et al. Cochrane handbook for systematic reviews of interventions version 6.1. London: Cochrane Collaboration; 2020. https:/doi.org/10.1002/9781119536604.

52. Matsumoto H, Matsumura K, Yamamoto Y, Fujii K, Tsujimoto S, Otagaki $M$, et al. Prognostic value of psoas muscle mass index in patients with NonST-SegmentElevation myocardial infarction: a prospective observational study. J Am Heart Assoc. 2020;9(19):e017315. https://doi. org/10.1161/JAHA.120.017315 
53. Nozaki Y, Yamaji M, Nischiguchi S, Fukutani N, Tashiro Y, Shirooka H, et al. Sarcopenia predicts adverse outcomes in an elderly outpatient population with New York heart association class II-IV heart failure: a prospective cohort study. Aging Med Healthcare. 2019;10(2):53-61. https://doi.org/10.33 879/AMH.2019.1809.

54. Pacifico J, Geerlings MAJ, Reijnierse EM, Phassouliotis C, Lim WK, Maier AB. Prevalence of sarcopenia as a comorbid disease: a systematic review and meta-analysis. Exp Gerontol. 2020;131:110801. https://doi.org/10.1016/j. exger.2019.110801

55. Bai T, Fang F, Li F, Ren Y, Hu J, Cao J. Sarcopenia is associated with hypertension in older adults: a systematic review and meta-analysis. BMC Geriatr. 2020;20(1):279. https://doi.org/10.1186/s12877-020-01672-y.

56. Trierweiler H, Kisielewicz G, Hoffmann Jonasson T, Rasmussen Petterle R, Aguiar Moreira C, Zeghbi Cochenski Borba V. sarcopenia: a chronic complication of type 2 diabetes mellitus. Diabetol Metab Syndr. 2018;10(1): 25. https://doi.org/10.1186/s13098-018-0326-5.

57. Fukuda T, Bouchi R, Takeuchi T, Nakano Y, Murakami M, Minami I, et al. Association of diabetic retinopathy with both sarcopenia and muscle quality in patients with type 2 diabetes: a cross-sectional study. BMJ Open Diabetes Res Care. 2017;5(1):e000404. https://doi.org/10.1136/bmjdrc-2017000404.

58. Stenholm S, Harris TB, Rantanen T, Visser M, Kritchevsky SB, Ferrucci L. Sarcopenic obesity: definition, cause and consequences. Curr Opin Clin Nutr Metab Care. 2008;11(6):693-700. https://doi.org/10.1097/MCO.0b013e328312 c37d.

59. Bouchonville MF, Villareal DT. Sarcopenic obesity: how do we treat it? Curr Opin Endocrinol Diabetes Obes. 2013;20(5):412-9. https://doi.org/10.1097/ 01.med.0000433071.11466.7f.

60. Jin J. JAMA patient page. Obesity and the heart. JAMA. 2013;310(19):2113. https://doi.org/10.1001/jama.2013.281901.

61. Petrie JR, Guzik TJ, Touyz RM. Diabetes, hypertension, and cardiovascular disease: clinical insights and vascular mechanisms. Can J Cardiol. 2018;34(5): 575-84. https://doi.org/10.1016/j.cjca.2017.12.005

62. Piche ME, Tchernof A, Despres JP. Obesity phenotypes, diabetes, and cardiovascular diseases. Circ Res. 2020;126(11):1477-500. https://doi.org/1 $0.1161 /$ CIRCRESAHA.120.316101.

63. Rosendorff C, Lackland DT, Allison M, Aronow WS, Black HR, Blumenthal RS, et al. Treatment of hypertension in patients with coronary artery disease: a scientific statement from the American Heart Association, American College of Cardiology, and American Society of Hypertension. Circulation. 2015; 131(19):e435-70. https://doi.org/10.1161/CIR.0000000000000207.

64. Elgendy IY, Bavry AA, Gong Y, Handberg EM, Cooper-DeHoff RM, Pepine CI. Long-term mortality in hypertensive patients with coronary artery disease: results from the US cohort of the international verapamil (SR)/Trandolapril study. Hypertension. 2016;68(5):1110-4. https://doi.org/10.1161/ HYPERTENSIONAHA.116.07854.

65. Matheus AS, Tannus LR, Cobas RA, Palma CC, Negrato CA, Gomes MB. Impact of diabetes on cardiovascular disease: an update. Int J Hypertens. 2013:2013:653789-15. https://doi.org/10.1155/2013/653789.

66. Goodale T, Sadhu A, Petak S, Robbins R. Testosterone and the heart Methodist Debakey Cardiovasc J. 2017;13(2):68-72. https://doi.org/10.14797/ mdcj-13-2-68

67. Oskui PM, French WJ, Herring MJ, Mayeda GS, Burstein S, Kloner RA. Testosterone and the cardiovascular system: a comprehensive review of the clinical literature. J Am Heart Assoc. 2013;2(6):e000272. https://doi.org/10.11 61/JAHA.113.000272

68. Leandro-Merhi VA, de Aquino JL. Determinants of malnutrition and postoperative complications in hospitalized surgical patients. J Health Popul Nutr. 2014;32(3):400-10. https://doi.org/10.1016/S0261-5614(13)60457-4.

69. Ben-Ishay O, Gertsenzon H, Mashiach T, Kluger Y, Chermesh I. Malnutrition in surgical wards: a plea for concern. Gastroenterol Res Pract. 2011;2011:1-4. https://doi.org/10.1155/2011/840512.

70. Karu I, Starkopf J, Zilmer K, Zilmer M. Growth factors serum levels in coronary artery disease patients scheduled for bypass surgery: perioperative dynamics and comparisons with healthy volunteers. Biomed Res Int. 2013; 2013:985404-5. https://doi.org/10.1155/2013/985404.

71. Gola M, Bonadonna S, Doga M, Giustina A. Clinical review: growth hormone and cardiovascular risk factors. J Clin Endocrinol Metab. 2005;90(3):1864-70. https://doi.org/10.1210/jc.2004-0545.

72. Liu P, Hao Q, Hai S, Wang H, Cao L, Dong B. Sarcopenia as a predictor of allcause mortality among community-dwelling older people: a systematic review and meta-analysis. Maturitas. 2017;103:16-22. https://doi.org/10.1016/ j.maturitas.2017.04.007.

73. Sobestiansky S, Michaelsson K, Cederholm T. Sarcopenia prevalence and associations with mortality and hospitalisation by various sarcopenia definitions in 85-89 year old community-dwelling men: a report from the ULSAM study. BMC Geriatr. 2019;19(1):318. https://doi.org/10.1186/s12877-01 9-1338-1.

74. Beaudart C, Zaaria M, Pasleau F, Reginster JY, Bruyere O. Health outcomes of sarcopenia: a systematic review and Meta-analysis. PLoS One. 2017;12(1): e0169548. https://doi.org/10.1371/journal.pone.0169548.

75. Shachar SS, Williams GR, Muss HB, Nishijima TF. Prognostic value of sarcopenia in adults with solid tumours: a meta-analysis and systematic review. Eur J Cancer. 2016;57:58-67. https://doi.org/10.1016/j.ejca.2015.12.030.

76. Zhang XM, Dou QL, Zeng Y, Yang Y, Cheng ASK, Zhang WW. Sarcopenia as a predictor of mortality in women with breast cancer: a meta-analysis and systematic review. BMC Cancer. 2020;20(1):172. https://doi.org/10.1186/s12 885-020-6645-6.

77. Wu Y, Wang W, Liu T, Zhang D. Association of Grip Strength With Risk of All-Cause Mortality, Cardiovascular Diseases, and Cancer in CommunityDwelling Populations: A Meta-analysis of Prospective Cohort Studies. J Am Med Dir Assoc. 2017;18(6):551 e517-35

78. Gubelmann C, Vollenweider P, Marques-Vidal P. No association between grip strength and cardiovascular risk: the CoLaus population-based study. Int J Cardiol. 2017;236:478-82. https://doi.org/10.1016/j.ijcard.2017.01.110.

79. Thompson DR, Yu CM. Quality of life in patients with coronary heart disease-l: assessment tools. Health Qual Life Outcomes. 2003;1(1):42. https:// doi.org/10.1186/1477-7525-1-42.

80. Bahall M, Legall G, Khan K. Quality of life among patients with cardiac disease: the impact of comorbid depression. Health Qual Life Outcomes. 2020;18(1):189. https://doi.org/10.1186/s12955-020-01433-w.

81. Korsnes JS, Davis KL, Ariely R, Bell CF, Mitra D. Health care resource utilization and costs associated with nonfatal major adverse cardiovascular events. J Manag Care Spec Pharm. 2015;21(6):443-50. https://doi.org/10.1 8553/jmcp.2015.21.6.443

82. Pipek LZ, Baptista CG, Nascimento RFV, Taba JV, Suzuki MO, Do Nascimento FS, et al. The impact of properly diagnosed sarcopenia on postoperative outcomes after gastrointestinal surgery: a systematic review and metaanalysis. PLoS One. 2020;15(8):e0237740. https://doi.org/10.1371/journal. pone.0237740.

\section{Publisher's Note}

Springer Nature remains neutral with regard to jurisdictional claims in published maps and institutional affiliations.

Ready to submit your research? Choose BMC and benefit from:

- fast, convenient online submission

- thorough peer review by experienced researchers in your field

- rapid publication on acceptance

- support for research data, including large and complex data types

- gold Open Access which fosters wider collaboration and increased citations

- maximum visibility for your research: over $100 \mathrm{M}$ website views per year

At BMC, research is always in progress.

Learn more biomedcentral.com/submissions 